\title{
Effects of Exogenous Lipid Peroxides on Mortality and Tissue Alterations in Japanese Pearl Oysters Pinctada fucata martensii
}

\author{
YOSHIYUKI SUGISHITA \\ Graduate School of Science and Technology, Nagasaki University, \\ 1-14 Bunkyo Machi, Nagasaki 852-8521, Japan
}

MizUKi HiRANO

Yamamoto Shinju Corporation, Inokusiura 374, Kamae, Oita 876-2402, Japan

Kenichi Tsutsumi

Graduate School of Science and Technology, Nagasaki University, 1-14 Bunkyo Machi, Nagasaki 852-8521, Japan

\author{
S. M. A. Mobin ${ }^{1}$
}

Department of Fish and Wildlife Resources, College of Natural Resources, University of Idaho, Moscow, Idaho 83844, USA

\author{
Kinya Kanai And KaZuma Yoshikoshi*
}

Faculty of Fisheries, Nagasaki University, 1-14 Bunkyo Machi, Nagasaki 852-8521, Japan

\begin{abstract}
The effects of exogenous lipid peroxides, suspected to be a cellular injury factor that causes mass mortalities of cultured Japanese pearl oysters Pinctada fucata martensii, were investigated in vivo and in vitro. Cumulative mortalities of experimental oysters exposed to oxidized oils in suspension (fish feed oil) or emulsion (methyl linoleate) were approximately $40 \%$ after 8 or 9 weeks, whereas mortalities were $0.0 \%$ (suspension) and $5.6 \%$ (emulsion) in control oysters exposed to unoxidized oils. Pathological changes observed in experimental oysters were characterized by blebbing and necrosis of cells in various organs that had spread from the digestive organ and were identical to those observed in diseased oysters from natural mass mortalities. The thiobarbituric acid values of experimental oysters were consistently and significantly higher than those of control oysters. An in vitro exposure examination also demonstrated that oxidized oil caused conspicuous blebbing and necrosis in the epithelial cells of the digestive organ. These results suggest that organic pollution caused by suspended solids containing lipid peroxides, emulsion of oxidized oils, or both is a major environmental factor that chronically damages tissues of cultured oysters and can cause mass mortalities.
\end{abstract}

In the past three decades, the Japanese marine fish farming industry has rapidly expanded. Most expansion has taken place in western and southern Japan, areas previously occupied by pearl oyster and fish farms. Since 1993, production of Japanese pearl oysters Pinctada fucata martensii in Japan has been suffering because of mass mortalities of cultured oysters. Several reports describe viral or infectious agents as a cause (Kurokawa et al. 1999;

\footnotetext{
* Corresponding author: ykazuma@net.nagasaki-u.ac.jp

${ }^{1}$ Present address: Department of Agriculture and Animal Science, Northern Melbourne Institute of TAFE (NMIT), Cnr. Cooper Street and Dalton Road, Epping, Victoria 3076, Australia.
}

Received May 15, 2004; accepted January 8, 2005 Published online August 18, 2005
Miyazaki et al. 1999; Muroga et al. 1999); however, a causative agent was not definitively identified (e.g., Kurokawa et al. 1999; Muroga et al. 1999). Contact infection trials we conducted failed to reproduce mass mortality of oysters (Hirano et al. 2002). In addition, a recent study by Hirano et al. (in press) demonstrated no viral, bacterial, mycotic, or parasitic organisms in lesions of various organs of diseased oysters, thereby suggesting that the occurrence of mass mortality was associated with changes in environmental factors. The study also suggested the prevalence of an unknown cellular injury factor in oyster farms that causes characteristic lesions in various organs that had spread from the digestive organ of cultured oysters.

Rapid expansion of fish farms in the surrounding areas of pearl oyster farms in Japan has re- 
sulted in serious organic pollution of fish and oyster farms and surrounding waters (Hirata et al. 1994; Tsutsumi 1995; Yokoyama 2002). In recent years, particularly since the $1990 \mathrm{~s}$, the use of moist and dry pellet feeds for fish culture has markedly risen. These feeds contain intentionally or unintentionally added toxins, such as histamine and oxidized fats (Hendricks and Bailey 1989; Lovell 1989). The pellets are usually enriched with feed oil rich in n-3 polyunsaturated fatty acids, which generate lipid peroxides through auto-oxidation unless antioxidant protection is incorporated in the feed. Because lipid peroxides and their derivatives are known to be highly toxic to animal cells (e.g., Watanabe and Hashimoto 1968; Tappel 1973; Paik et al. 1976; Paik and Kaneda 1978; Kaneda and Miyazawa 1987), waste feed and feces-containing undigested feed are suspected to be major organic pollutants in oyster farms and surrounding waters. Because the reaction of lipid peroxides with thiobarbituric acid (TBA) has been widely adopted as a sensitive assay method for lipid peroxidation in animal tissue (Kohn and Liversedge 1944; Patton and Kurtz 1951; Kikugawa and Kosugi 1993), the objective of this study was to use this assay method to clarify the pathological effects of lipid peroxides on oysters and to investigate the possibility of lipid peroxides as a causative agent of mass mortalities of cultured oysters.

\section{Methods}

Pathological examinations and assays of tissue TBA values were conducted through a series of four experiments. The first experiment examined the effects of chronic exposure of oysters to oxidized and unoxidized fish feed oils existing in suspension or emulsion (or both) prepared from dry pellet fish feed. The second experiment examined the effects of chronic exposure of oysters to oxidized and unoxidized oils (methyl linoleate [ML]) in emulsion. The third experiment was conducted to assess whether any pathological effects of oysters were derived from feeding only phytoplankton. The fourth experiment examined the effects of exposure of oysters to oxidized and unoxidized ML in vitro.

Feed oil preparation for the first and second experiments.-Ika feed oil (Riken Vitamin, Tokyo, Japan) was used in this study. Oxidized oil (peroxide value $[\mathrm{POV}]=52.8$ milliequivalents $[\mathrm{meq}] /$ $\mathrm{kg}$ ) was prepared by aerating fresh oil at $80^{\circ} \mathrm{C}$ for $30 \mathrm{~h}$ and then aerating it for $8 \mathrm{~h} / \mathrm{d}$ at room temperature for $10 \mathrm{~d}$. The oxidized oil was held at room temperature until use. The POV of unoxidized oil was $4.5 \mathrm{meq} / \mathrm{kg}$. Unoxidized oil was supplemented with DL- $\alpha$-tocopherol acetate as an antioxidant at a concentration of $5 \%$ of feed oil (weight per weight $[w / w])$. Dry pellet feed for yellowtail jacks Seriola lalandi from three manufacturers (Marubeni Nisshin Feed Co., Ltd., Tokyo, Japan; Nosan Corporation, Kanagawa, Japan; and Hayashikane Sangyo Co., Ltd., Shimonoseki, Japan) was mixed in equal amounts and then milled with an electric mixer and a porcelain mortar. The milled feed was soaked with either the oxidized or unoxidized feed oil at a concentration of $20 \%$ of the pellet feed $(\mathrm{w} / \mathrm{w})$. Unoxidized oil was further supplemented with L-ascorbic acid and catechins (THEA-FRAN 90S; Ito En, Ltd., Tokyo, Japan) at a concentration of $1 \%$ of feed oil (w/w). The L-ascorbic acid and catechins were used to minimize further oxidation of feed oil in storage and to minimize effects of lipid peroxides in the experimental diet of control oysters. The dry pellet feeds containing oxidized or unoxidized feed oil were suspended in filtered seawater with an electric mixer and then filtered with a plankton net (mesh size, $50 \mu \mathrm{m}$ ).

Methyl linoleate preparation.-Oxidized ML (POV $=204.9 \mathrm{meq} / \mathrm{kg}$ ) was prepared by oxygenating fresh oil for $7 \mathrm{~d}(1 \mathrm{~h} / \mathrm{d})$ at room temperature and then by auto-oxidation at room temperature for 1 month. The oxidized oil was stored at $-80^{\circ} \mathrm{C}$ until use. The POV of unoxidized ML (no antioxidant was used) was $3.0 \mathrm{meq} / \mathrm{kg}$. Lecion LP-1 (Riken Vitamin), an emulsifier, was used for emulsification. The ratio of Lecion LP-1 and oil was 3:1.

Test oysters and rearing apparatus.- Two-yearold Japanese pearl oysters of the same hatcheryreared strain (Nishimura Shinju Corporation, Nagasaki, Japan), presumed to be healthy according to their external appearance, were used for all experiments. Initial average body weights of test oysters in the first, second, and third experiments were $27.2,27.7$, and $29.7 \mathrm{~g}$, respectively. Test oysters were acclimated to the laboratory environment for $1 \mathrm{~d}$ before use. Eighty test oysters were reared in 1,000-L polycarbonate tanks supplied with filtered seawater. Seawater was renewed daily and aerated continuously at approximately $6 \mathrm{~L} / \mathrm{min}$. Test oysters were fed cultured phytoplankton (Chaetoceros spp. and Pavlova sp.). The first experiment was conducted from June to July 2001, the second experiment was conducted from August to September 2002, and the third experiment was conducted from October to December 2002. Water temperatures varied from $21.8^{\circ} \mathrm{C}$ to $27.3^{\circ} \mathrm{C}$ in the first ex- 
periment, from $26.5^{\circ} \mathrm{C}$ to $23.4^{\circ} \mathrm{C}$ in the second experiment, and from $22.0^{\circ} \mathrm{C}$ to $24.0^{\circ} \mathrm{C}$ in the third experiment. During all experiments, dissolved oxygen (DO) varied between 5.6 and $6.5 \mathrm{mg} / \mathrm{L}$ and $\mathrm{pH}$ varied between 7.7 and 8.4.

Exposure procedures.-In the first experiment, the suspension of dry pellet fish feed containing oxidized feed oil was placed into a 20 -L plastic container installed on the rearing tanks that contained the experimental oysters. Approximately 20 $\mathrm{g}$ of pellet feed suspension (suspended solids [SS]) in $20 \mathrm{~L}$ of seawater was added to the rearing tank over a period of $8 \mathrm{~h}$. Control oysters were exposed to a suspension of dry pellet fish feed containing unoxidized oil following the same protocol described for the experimental oysters. After adding SS, cultured phytoplankton (equal amounts Chaetoceros and Pavlova) was administered at a concentration of approximately 5\% of the oyster's body weight (soft parts) once a day. To measure plankton weight, plankton cultures of various concentrations were centrifuged and precipitations were weighed; thus, the relationship between plankton concentrations and plankton wet weight was obtained. Using this relationship, we determined appropriate volumes of plankton cultures to administer. The weight of soft body parts was obtained from the relationship of total oyster weight (weight of valves plus weight of soft body parts) and weight of soft body parts. Although emaciation of test oysters advanced as time progressed, we used initial body weight to determine the plankton weight to administer and did not adjust to changes in oyster body weight. Initial TBA values of SS containing oxidized and unoxidized oil were 2,090 and $392 \mathrm{nmol} / \mathrm{g}$ SS (wet weight), respectively. The TBA values were assayed according to the method presented by Uchiyama and Mihara (1978).

In the second experiment, experimental and control oysters were exposed to oxidized and unoxidized ML that were added to rearing tanks in emulsion at a concentration of $2.5 \mathrm{mg} / \mathrm{L}$. Cultured phytoplankton at approximately $5 \%$ of the oyster's body weight (soft parts; equal amounts of Chaetoceros and Pavlova) was mixed with emulsified ML and added to the rearing tanks. Additional cultured phytoplankton at approximately $5 \%$ of the oyster's body weight (soft parts) was administered following the same protocol described for the first experiment. In the third experiment, cultured phytoplankton alone (approximately 5\% of the oyster's body weight) was administered every $12 \mathrm{~h}$ following the same protocol described for the first experiment.

Sampling of test oysters. - Tissues of 7 oysters from each of the experimental and control groups were sampled for histological examination and TBA value assessment at $0,1,2,4$, and 8 weeks after starting the experiment.

Assay of tissue TBA values.-Sampled oysters were dissected and soft body parts were stored at $-80^{\circ} \mathrm{C}$. Using the homogenates of the soft body parts (whole body), TBA values were assayed according to Uchiyama and Mihara's (1978) method and expressed as nmol malondialdehyde/mg protein. Tissue protein concentration was determined according to Lowry et al. (1951).

Light microscopy.-Oysters were dissected and soft body parts were fixed in chilled seawater that contained $20 \%$ formalin. After dissection, fixed tissues were dehydrated in a graded ethanol series and embedded in paraffin. Paraffin sections $3 \mu \mathrm{m}$ thick were cut and stained with hematoxylin and eosin (HE).

Statistical analysis.-In the first, second, and third experiments, the TBA value was the measured response variable. Two-way analysis of variance (ANOVA) was applied to the data in the first and second experiments to determine differences in mean responses to treatments and time levels. If the ANOVA result was significant, Tukey's multiple comparison procedure (with equal sample size) was applied to identify means that were significantly different. Interaction effects were also evaluated. The ANOVA was also done for the third experiment. Differences in mortality between experimental and control oysters were analyzed with Fisher's exact probability test.

The fourth experiment.-Two-year-old Japanese pearl oysters of the same strain used in the first, second, and third experiments that had a healthy appearance (average body weight, $23.4 \mathrm{~g}$ ) were used in the fourth experiment. Test oysters $(n=$ 36) were opened and whole soft body parts were excised in toto. After removing the adductor muscle, mantle, pedal, and gill tissues, visceral masses were sagittally cut into two pieces with a sterilized razor blade and rinsed thoroughly with filtersterilized (pore size $=0.22 \mu \mathrm{m}$ ) seawater. Oxidized and unoxidized ML prepared for the second experiment were used in the fourth experiment. Experimental and control tissues were exposed to oxidized and unoxidized ML emulsified in filtersterilized seawater following the same protocol described for the second experiment at concentrations of 10,100 , and $1,000 \mathrm{mg} / \mathrm{L}$. No antibiotics 


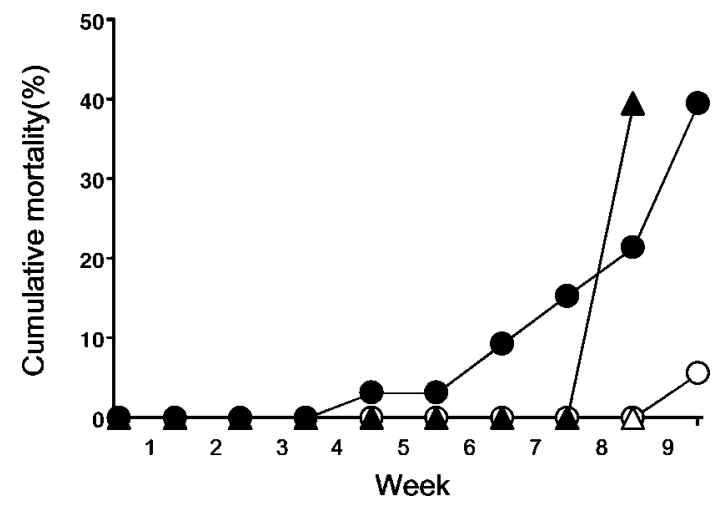

FIgURE 1.-Cumulative mortalities of cultured Japanese pearl oysters in the first (triangles) and second (circles) laboratory experiments conducted in 2001 and 2002. Solid symbols indicate experimental oysters exposed to dry pellet fish feed containing oxidized feed oil and open symbols indicate control oysters exposed to dry pellet fish feed containing unoxidized feed oil.

were used during the preparation of test media. The test media were kept at $20^{\circ} \mathrm{C}$, gently aerated with filtered air through the use of a cartridge filter (pore size $=0.45 \mu \mathrm{m}$ ), and renewed every $12 \mathrm{~h}$. For incubation, $200-\mathrm{mL}$ beakers containing $50 \mathrm{~mL}$ of the test media were employed. At concentrations of 10 and $100 \mathrm{mg} / \mathrm{L}, 3$ oysters were examined for each exposure time of 12 and $24 \mathrm{~h}$. At a concentration of $1,000 \mathrm{mg} / \mathrm{L}, 8$ oysters were used for each exposure time $(6,12$, or $24 \mathrm{~h})$. After incubation for 6,12 , or $24 \mathrm{~h}$, experimental and control tissues were fixed in chilled $4 \%$ paraformaldehyde-3\% glutaraldehyde in $0.1 \mathrm{M}$ cacodylate buffer $(\mathrm{pH}$ 7.3), dehydrated in a graded ethanol series, and embedded in paraffin wax. Paraffin sections $3 \mu \mathrm{m}$ thick were stained with HE.

\section{Results}

\section{Mortality in the First, Second, and Third Experiments}

In the first experiment, the mortality of experimental oysters occurred during the last phase (8th week), and the cumulative mortalities of experimental and control oysters were $39.5 \%$ and $0 \%$, respectively (Figure 1). In the second experiment, the mortality rate increased gradually from 4 weeks after the start of the experiment; overall, cumulative mortalities of experimental and control oysters were $39.5 \%$ and $5.6 \%$, respectively (Figure $1)$. There were significant differences in mortalities between experimental and control oysters in the first experiment $(P<0.001 ; 8$ th week $)$ and the second experiment $(P<0.05$; 9 th week). All test oysters survived during the third experiment.

\section{Gross Anatomy}

At the end of the first experiment, the experimental oysters that survived either partially or completely lost the marginal projections of their valves (Figure 2). They were highly emaciated, and their stomach and digestive diverticula (DD) were atrophied. The DD of most experimental oysters had lost their normal dark green color and had become pale in color, which was identical to the DD of
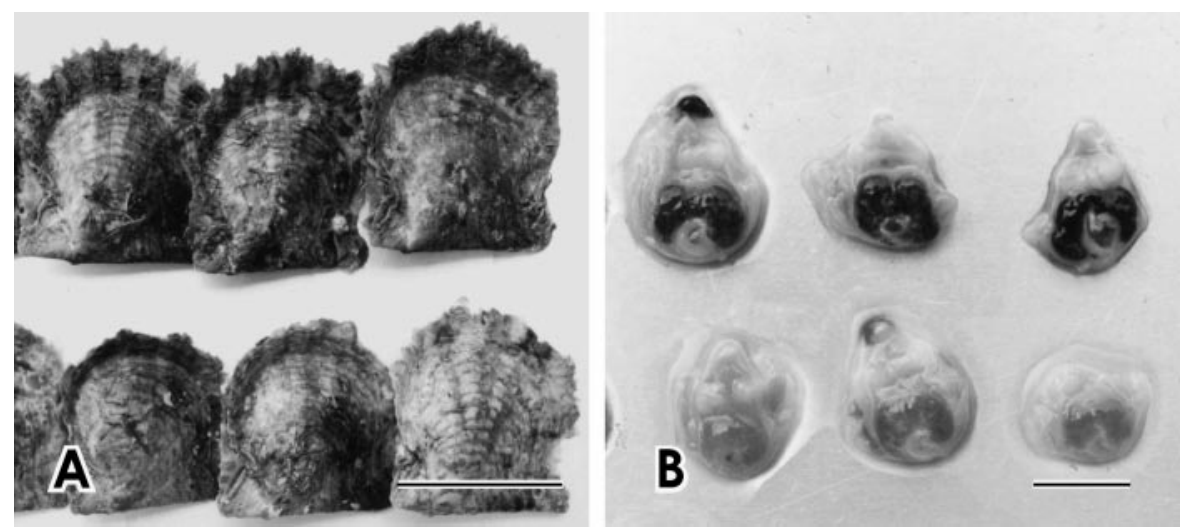

FIGURE 2.-(A) External and (B) internal views of control (upper row) Japanese pearl oysters exposed to dry pellet fish feed containing unoxidized feed oil and experimental (lower row) Japanese pearl oysters exposed to dry pellet fish feed containing oxidized feed oil at the end of the first laboratory experiment conducted in 2001. The scale bars in (A) and (B) represent 5 and $1 \mathrm{~cm}$, respectively. 

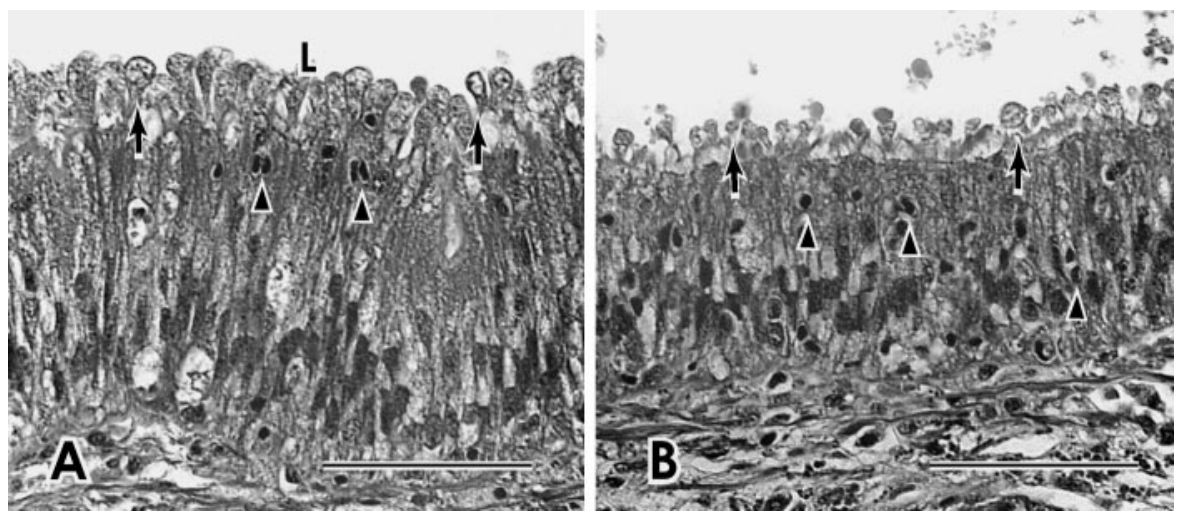

FIGURE 3.-Light micrographs showing the epithelia of (A) the stomach and (B) a duct of the digestive diverticula of experimental Japanese oysters exposed to dry pellet fish feed containing oxidized feed oil after 4 weeks in the first laboratory experiment conducted in 2001. Arrows indicate blebbing in the apical surface of the epithelial cells, arrowheads indicate mitotic figures, and the letter L indicates the gut lumen. Scale bars represent $50 \mu \mathrm{m}$.

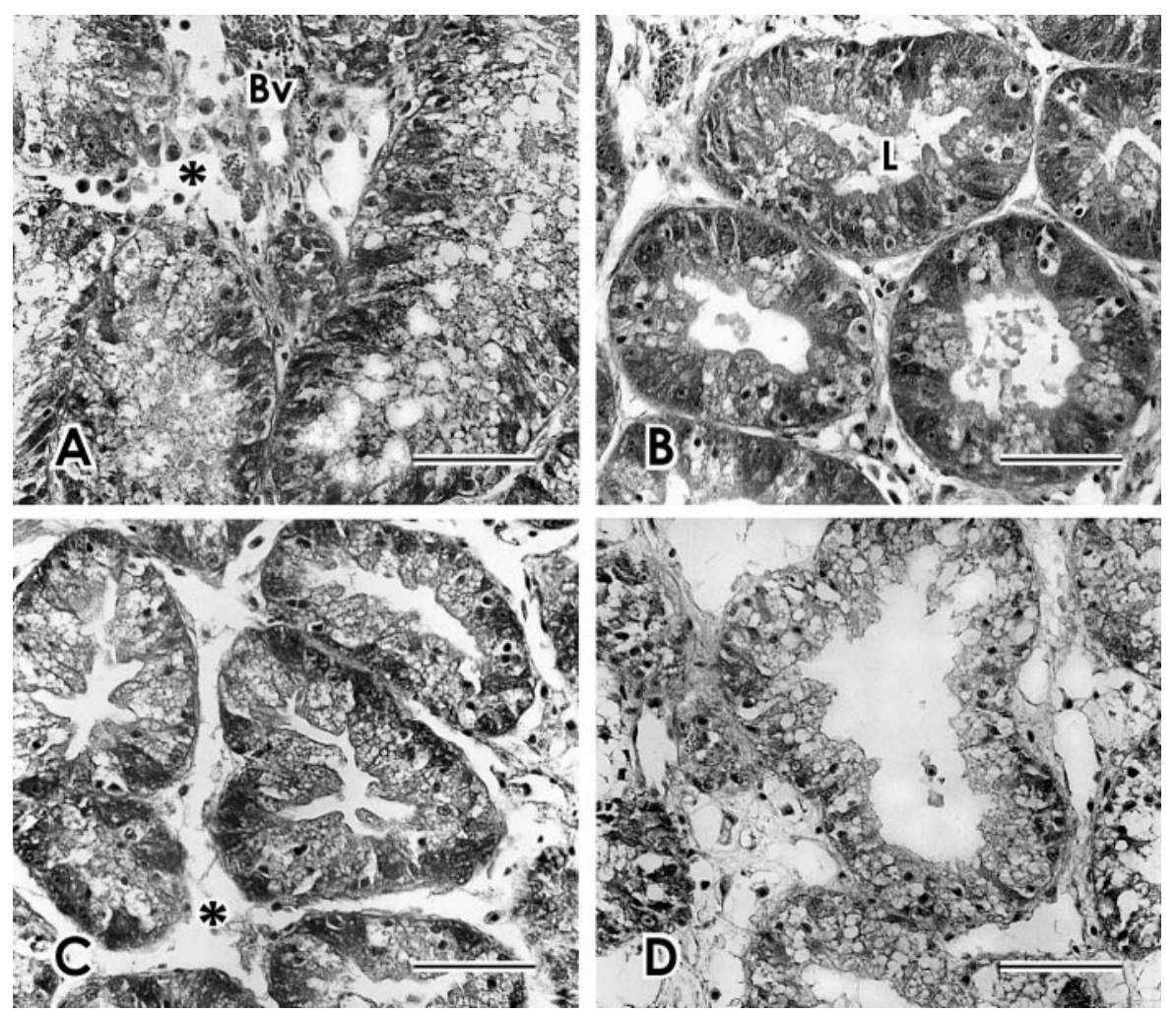

FIGURE 4.--Light micrographs showing the digestive diverticula of experimental Japanese pearl oysters exposed to dry pellet fish feed containing oxidized feed oil after (A and B) 2 weeks and (C and D) 4 weeks in the first laboratory experiment conducted in 2001. Asterisks show necrosis of the interstitial connective tissue. Infiltration of the blood cells is seen in the connective tissue (A). Droplets derived from the crystalline style are seen in the gut lumen (B). The abbreviation $\mathrm{Bv}$ indicates a blood vessel and the letter $\mathrm{L}$ indicates the gut lumen. Scale bars represent $50 \mu \mathrm{m}$. 

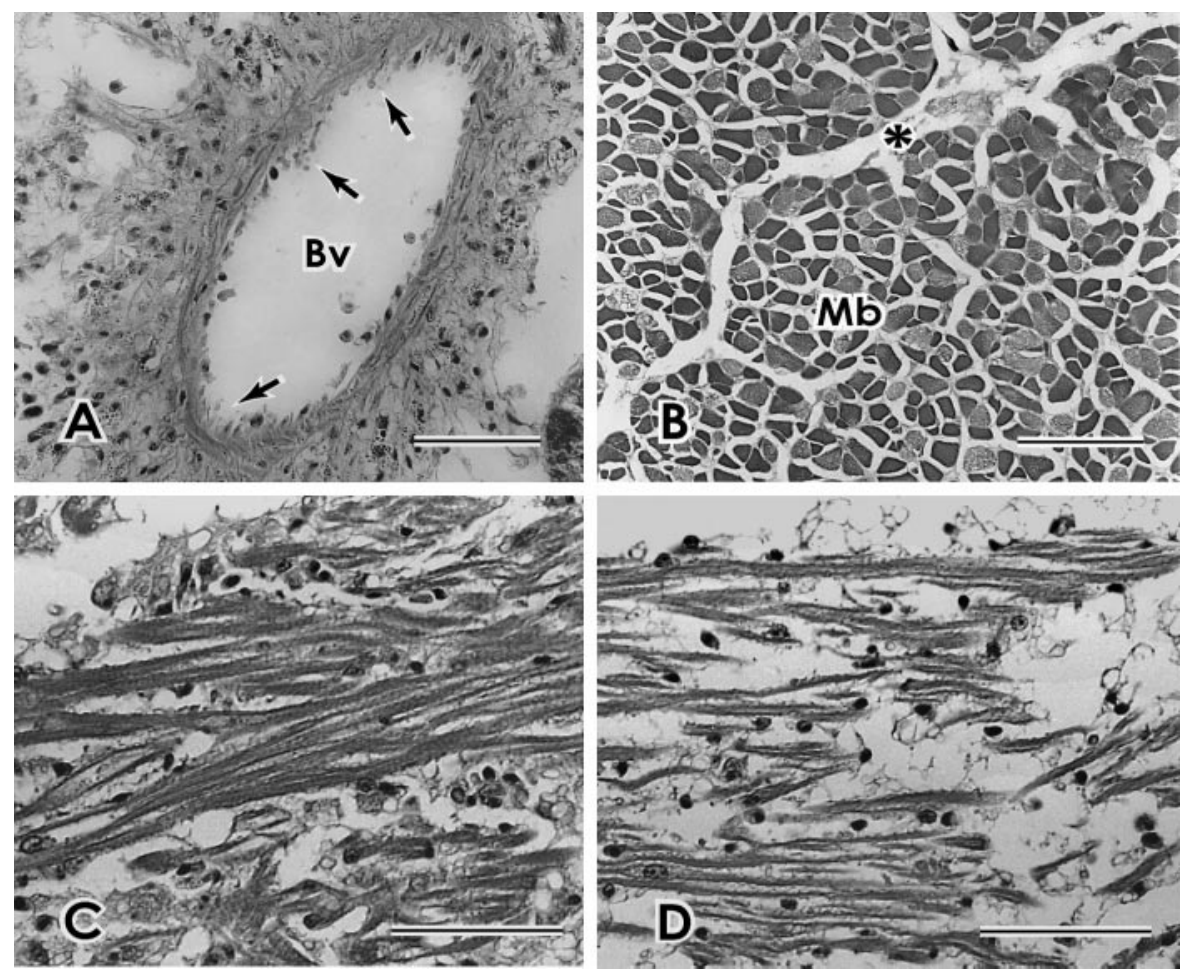

FIGURE 5.- Light micrographs showing (A) a blood vessel, (B) a cross section of the adductor muscle, and (C and D) cardiac muscle fibers of experimental Japanese pearl oysters exposed to dry pellet fish feed containing oxidized feed oil (A, B, and D) and a control oyster exposed to dry pellet fish feed containing unoxidized feed oil (C) after 4 weeks in the first laboratory experiment conducted in 2001. Arrows indicate necrotic endothelial cells and the asterisk indicates necrotic connective tissue (perimysium). The abbreviation Bv indicates a blood vessel, and the abbreviation $\mathrm{Mb}$ indicates a muscle fiber bundle. Scale bars represent $50 \mu \mathrm{m}$.

moribund oysters sampled from natural mass mortalities (Figure 2). These pathological changes were less severe or absent in control oysters. Gross pathology observed in the second experiment was identical to that of the first experiment. In the third experiment, all experimental oysters appeared to be healthy until the end of the experiment.

\section{Histopathology}

Selected organs and tissues (i.e., the stomach, ducts of the DD, the DD, adductor muscle, cardiac muscles, and blood vessels of test oysters) were examined in all experiments. In the first experiment, remarkable blebbing and necrosis were observed in the epithelia of the stomach, ducts of the $\mathrm{DD}$, and the DD of experimental oysters from the earlier to later stages of the experiment, though these changes varied considerably among oysters (Figure 3). Affected epithelial cells of the stomach and ducts of the DD were necrotic or atrophied due to loss of the cytoplasm by blebbing and subsequently sloughed off, and mitotic figures were frequently observed (Figure 3). Some experimental oysters had normal structure of the DD that was probably a result of cell regeneration (Figure 4). The number and cell size of epithelial cells of the DD tended to decrease as time progressed. Staining intensity of the epithelial cells of the DD also tended to decrease, and the number of empty vacuoles increased (Figure 4). In addition, necrosis of the interstitial connective tissue between the DD was clearly observed after 2 weeks (Figure 4) and became more apparent as time progressed. After 4 weeks, necrosis of the endothelial cells in small and large blood vessels was frequently observed (Figure 5), and necrosis of muscle fibers and the connective tissue of the adductor muscle (epimysium and perimysium; Figure 5) and necrosis of the endothelial tissue and atrophy of the cardiac muscle fibers were clearly observed after 4 weeks (Figure 5). The degree of lesions in organs other than the digestive organ varied considerably among oysters. Although such pathological alterations were also observed infrequently in control 


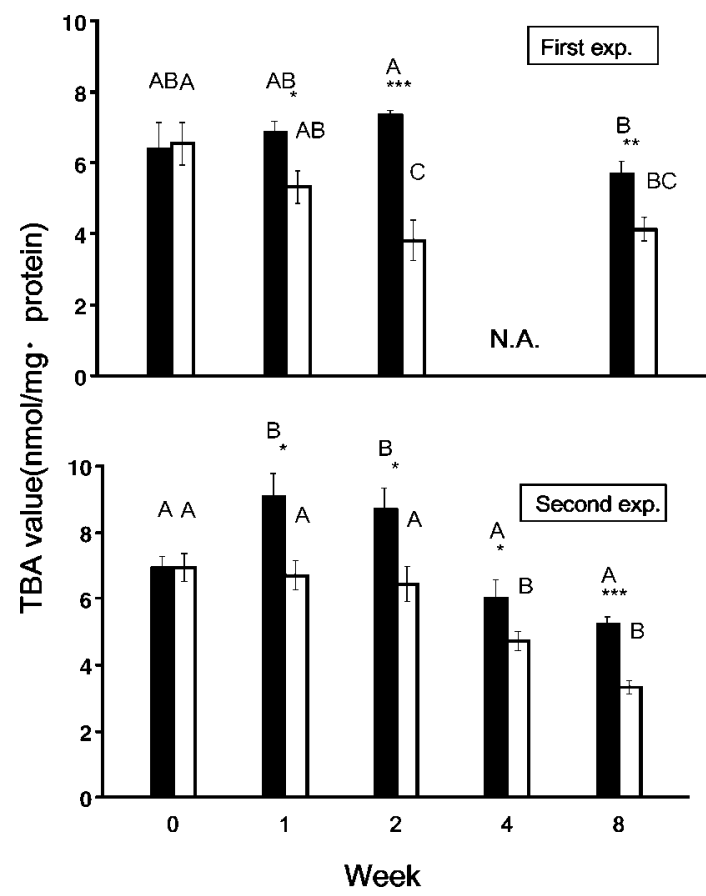

FIgURE 6.-Changes in thiobarbituric acid (TBA) values of Japanese pearl oysters in the first and second laboratory experiments conducted in 2001 and 2002. Solid columns indicate experimental oysters exposed to oxidized oils, and open columns indicate control oysters exposed to unoxidized oils. Vertical bars in columns indicate SEs. Capital letters in the figure indicate the effect of time and asterisks the effect of treatment. Different letters indicate a significant difference $(P<0.05)$; the significance of the asterisks is as follows: $P<0.05^{*}$, $P<0.01^{* *}$, and $P<0.001^{* * *}$. The abbreviation N.A. means not assayed.

oysters, the degree of lesions in all organs was significantly less severe when compared with experimental oysters.

The results obtained in the second experiment appeared to be identical with those of the first experiment, although pathological conditions of both experimental and control oysters were worse than in the first experiment. In the third experiment, no remarkable changes in the tissue structure of sampled organs were observed.

\section{TBA Values}

In both the first and second experiments, the TBA values of experimental oysters were consistently higher than those of control oysters (Figure $6)$. In the first experiment, both the treatment $(P$ $<0.001)$ and time period $(P<0.01)$ caused significant effects on the lipid peroxidation (measured by TBA value). The treatment $\times$ time period in-

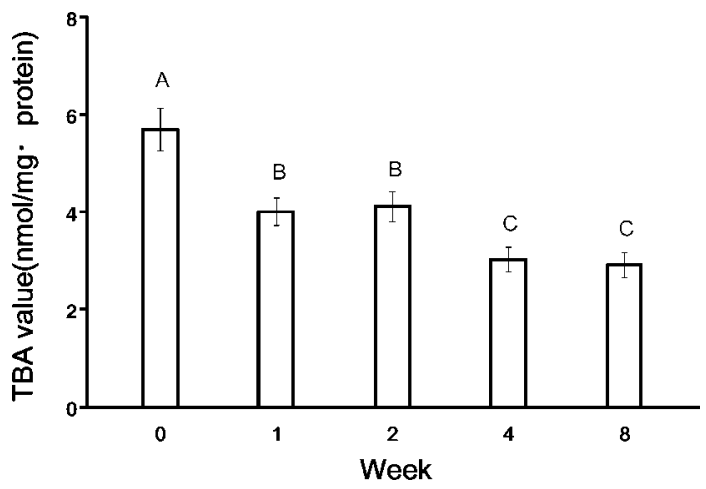

FIGURE 7.-Changes in thiobarbituric acid (TBA) values of Japanese pearl oysters fed cultured phytoplankton in the third laboratory experiment conducted in 2002. Vertical bars indicate SEs; different letters indicate significant differences $(P<0.05)$.

teraction effect was also significant $(P<0.01)$. In the second experiment, both the treatment and time period caused significant $(P<0.001)$ effects on the lipid peroxidation; however, the treatment $\times$ time period interaction effect was not significant $(P=0.063)$. At earlier stages of the experiments, TBA values of experimental oysters increased; in contrast, the TBA values of control oysters decreased or were unchanged. In the later stages of the experiment, TBA values of experimental oysters decreased (Figure 6). Changes in TBA values of test oysters fed cultured phytoplankton alone in the third experiment were similar to those of control oysters in the first experiment (Figure 7).

\section{The Fourth Experiment}

During the fourth experiment, remarkable blebbing and subsequent necrosis of the epithelial cells of the stomach and ducts of the DD and the DD were observed in experimental tissues, whereas no remarkable changes were found in control tissues. After incubation for $6 \mathrm{~h}$ in the 1,000-mg/L oxidized ML medium, conspicuous blebbing was observed in the apical portion of the epithelial cells of the stomach (Figure 8) and, to a lesser degree, in the epithelial cells of ducts of the DD (Figure 9). Some blebs in the stomach epithelium were sloughed off into the gut lumen. The DD and connective tissue underlying the epithelia of the stomach and ducts of the DD were unchanged at this stage. After incubation for $12 \mathrm{~h}$ in the 1,000-mg/ L oxidized ML medium, most epithelial cells of the stomach, ducts of the DD, and the DD of experimental tissues were affected (Figures 8 and 9). Epithelial cells of the stomach were highly trans- 

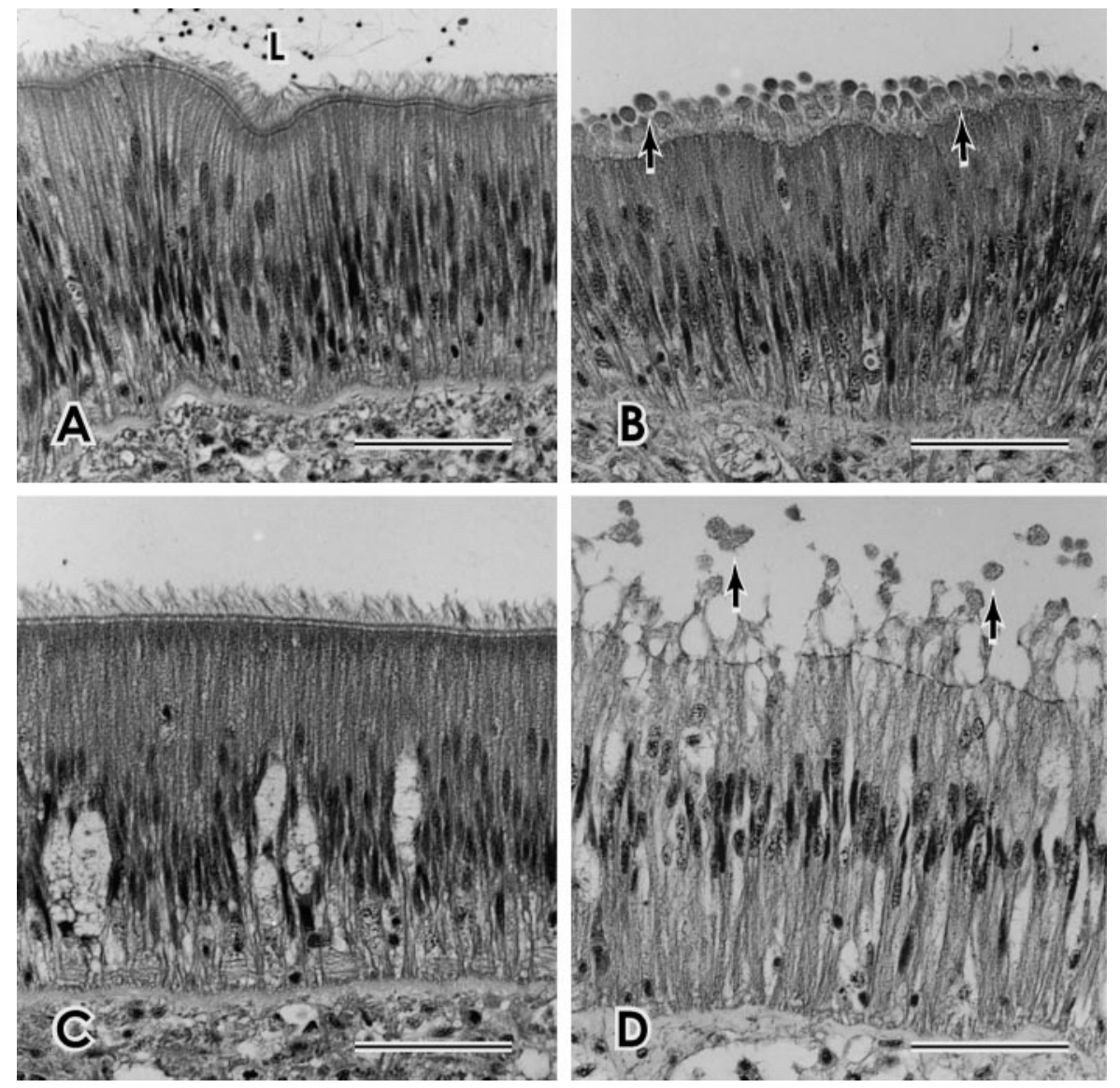

FIGURE 8.-Light micrographs showing cellular injury in the epithelial cells of the stomach exposed in 1,000 $\mathrm{mg} / \mathrm{L}$ of unoxidized (control) or oxidized (experimental) ML (methyl linoleate) media for 6 (A and B) or $12 \mathrm{~h}(\mathbf{C}$ and D). A and $\mathrm{C}$ show control tissues and B and D show experimental tissues. L indicates the gut lumen and arrows indicate blebbing and leakage of the cytoplasm. Scale bars are $50 \mu \mathrm{m}$.

parent as a result of severe loss of cytoplasm, although the nuclei were still slightly swelled (Figure 8 ). In the DD, functional epithelial cells containing numerous vacuoles participating in the intracellular digestion of food were highly necrotic; however, undifferentiated or immature cells (precursors of functional epithelial cells) remained slightly affected or unchanged (Figure 9). The connective tissue underlying the epithelia of the stomach, ducts of the DD, and the DD was unaffected. After incubation for $24 \mathrm{~h}$ in the 1,000-mg/L oxidized ML medium, extensive necrosis and destruction of epithelial tissues of the digestive organ involving the connective tissue were observed. Blebbing and necrosis of epithelial cells were first observed after incubation for $24 \mathrm{~h}$ in the $100-\mathrm{mg} / \mathrm{L}$ oxidized ML medium. No appreciable changes were observed in the $10-\mathrm{mg} / \mathrm{L}$ oxidized ML medium.

\section{Discussion}

The pathological changes observed in this study were characterized by cellular injury and necrosis of cells in various organs. It was evident that lipid peroxides in oxidized oils caused these pathological changes because exposure to unoxidized oil containing Lecion LP-1 induced no significant changes in the second and fourth experiments. The elevation of TBA values, which suggested lipid peroxidation in tissues (Kikugawa and Kosugi 1993), further adduced that lipid peroxides in oils were incorporated into the body and damaged cells in various organs. It was well established that lipid-radical interactions yield peroxides, which are 

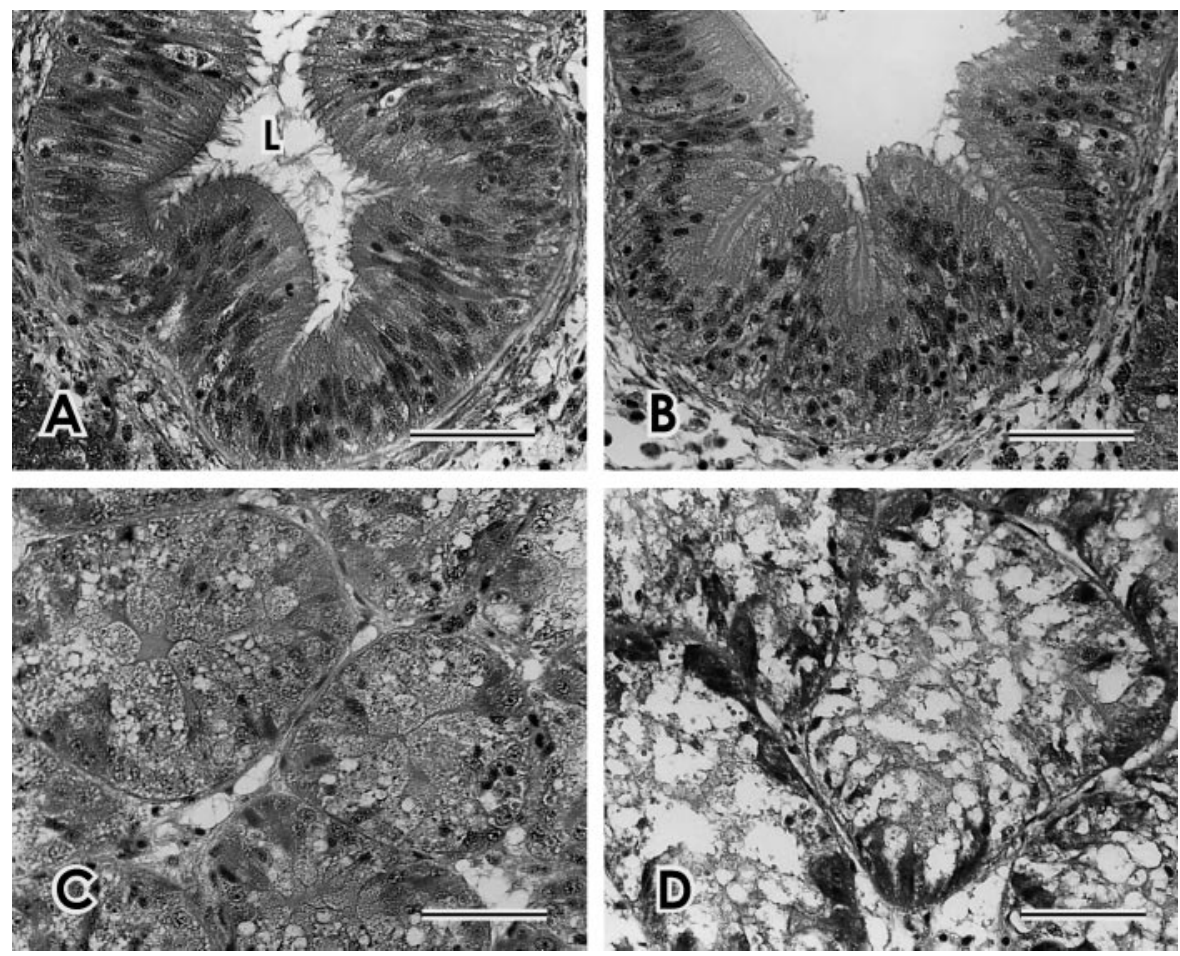

FIGURE 9.-Light micrographs showing cellular injury in Japanese pearl oyster epithelial cells of ducts of the DD (A and B) and the DD (C and D) exposed in 1,000 $\mathrm{mg} / \mathrm{L}$ of unoxidized (control) or oxidized (experimental) ML (methyl linoleate) media for 6 (A and B) or12 h (C and D). A and C show control tissues and B and D show experimental tissues. $\mathrm{L}$ indicates the gut lumen. Scale bars are $50 \mu \mathrm{m}$.

themselves reactive species, and initiate the subsequent reduction of another fatty acid. An autocatalytic chain reaction ensues (called propagation), resulting in extensive membrane, organellar, and cellular damage (Cotran et al. 1994). Accordingly, pathological changes observed in this study are consistent with those observed in higher vertebrate animals induced by free radicals (Cotran et al. 1994).

Sequential pathology in experimental oysters demonstrated significant lesions that started in the digestive organ and spread to other organs (i.e., adductor muscle, cardiac muscles, etc.). It is well known that oysters concentrate suspended food particles in their digestive tract by filter feeding (Numaguchi 1994). In this study, it is highly probable that filter feeding and ingestion concentrated SS and emulsion containing lipid peroxides in the digestive tract. It may be consistent with the cellular pathology of the digestive organ in vitro observed at higher concentrations of oxidized oils $(1,000$ or $100 \mathrm{mg} / \mathrm{L})$ both in this study and in natural mass mortalities (Hirano et al., in press). Epithelial cells of the stomach, ducts of the DD, and the DD itself possess well-developed microvilli and participate in the absorption of lipids. We consider that this is the reason why tissue alterations spread from the digestive organ.

The pathological changes observed in this study were identical to those of natural mass mortalities (Hirano et al., in press), although the progression of pathological changes in the first and second experiments was considerably faster than in natural mass mortalities. At Kamae farm in Oita prefecture, where mass mortality of cultured oysters occurs annually, healthy oysters transferred from Nagasaki prefecture toward the end of May began to die about 3 months after the transfer, and cumulative mortalities were as high as $29-56 \%$ at the end of November (our unpublished results). The faster progression of pathological changes in this study was probably a result of higher experimental concentrations of lipid peroxides. However, pathological changes found in this study are consistent with those of natural mass mortalities. This leads us to adopt a hypothesis that natural mass mortalities were caused by organic pollution from the 
suspension, emulsion, or both of pellet feed containing lipid peroxides in oyster farms.

Although we do not have sufficient information regarding the actual conditions of pollution due to lipid peroxides in oyster farms, discharge of waste feed and feces from fish farms is quite evident, as reported in salmonid net-pen culture (Brooks et al. 2002). The fish farms of western Japan do not have waste management systems. It is also evident that lipid peroxidation advanced in suspension or emulsion (or both) prepared from fish feed pellets as time progressed (our unpublished result). Further study on natural abundance of oxidized lipids in the environment will help establish the relationship between natural mass mortalities of pearl oysters and lipid peroxidation of fish feed pellets discharged from fish farms. Studies are also needed to standardize oxidized oil to a known standard (such as $t$-butylhydroperoxide) to allow for comparison with additional studies. Continued research on standardizing oxidized oil will lead to reproducible peroxide damage.

\section{Acknowledgments}

We thank Zen-o Yamamoto (Yamamoto Shinju Corporation) for providing research facilities. All experiments in this study were performed at the Yamamoto Shinju Corporation hatchery. We are grateful to Shingo Nishimura (Nishimura Shinju Corporation) for providing test oysters. We are also grateful to Professor Kenji Hara (Nagasaki University) for his valuable criticism in the analysis of TBA values and providing research facilities. Yamamoto Shinju Corporation provided a grant for this study.

\section{References}

Brooks, K. M., C. Mahnken, and C. Nash. 2002. Environmental effects associated with marine net-pen waste, with emphasis on salmon farming in the Pacific Northwest. Pages 159-203 in R. R. Stickney and J. P. McVey, editors. Responsible marine aquaculture. CABI Publishing, New York.

Cotran, R. S., V. Kumar, and S. L. Robbins. 1994. Cellular injury and cellular death. Pages $1-34$ in R. S. Cotran, V. Kumar, and S. L. Robbins, editors. Pathologic basis of disease. Saunders, Philadelphia.

Hendricks, J. D. and G. S. Bailey. 1989. Adventitious toxins. Pages 605-651 in J. E. Halver, editor. Fish nutrition. Academic Press, San Diego.

Hirano, M., K. Kanai, and Y. Yoshikoshi. 2002. Contact infection trials failed to reproduce the disease condition of mass mortality in cultured pearl oyster Pinctada fucata martensii. Fisheries Science 68: 700-702.

Hirano, M., Y. Sugishita, S. M. A. Mobin, K. Kanai, and K. Yoshikoshi. In press. An investigation of the pathology associated with mass mortality events in the cultured Japanese pearl oyster Pinctada fucata martensii at four farms in western Japan. Journal of Aquatic Animal Health 17.

Hirata, H., S. Kadowaki, and S. Ishida. 1994. Evaluation of water quality by observation of dissolved oxygen content in mariculture farms. Bulletin of the National Research Institute of Aquaculture Supplement 1:61-65.

Kaneda, T., and T. Miyazawa. 1987. Lipid peroxides and nutrition. World Review of Nutrition and Dietetics 50:186-214.

Kikugawa, K., and H. Kosugi. 1993. Detection and quantitative determination of lipid peroxidation in living bodies: thiobarbituric acid test. Japanese Journal of Toxicology and Environmental Health 39:1-19. (In Japanese with English abstract.)

Kohn, H. I., and M. Liversedge. 1944. On a new aerobic metabolite whose production by the brain is inhibited by apomorphine, emetine, ergotamine, epinephrine, and menadione. Journal of Pharmacology and Experimental Therapeutics 82:292-300.

Kurokawa, T., T. Suzuki, M. Okauchi, S. Miwa, K. Nagai, K. Nakamura, T. Honjo, K. Nakajima, K. Ashida, and S. Funakoshi. 1999. Experimental infections of a disease causing mass mortalities of Japanese pearl oyster Pinctada fucata martensii by tissue transplantation and cohabitation. Nippon Suisan Gakkaishi 65:241-251. (In Japanese with English abstract.)

Lovell, T. 1989. Nutrition and feeding of fish. Van Nostrand Reinhold, New York.

Lowry, O. H., N. J. Rosebrough, A. L. Farr, and R. J. Randall. 1951. Protein measurement with the folin phenol reagent. Journal of Biological Chemistry 193:265-275.

Miyazaki, T., K. Goto, T. Kobayashi, T. Kageyama, and M. Miyata. 1999. Mass mortalities associated with a virus disease in Japanese pearl oyster Pinctada fucata martensii. Diseases of Aquatic Organisms 37: $1-12$.

Muroga, K., Y. Inui, and T. Matsusato. 1999. Workshop "Emerging Diseases of Cultured Marine Mollusks in Japan." Fish Pathology 34:219-231. (In Japanese with English abstract.)

Numaguchi, K. 1994. Effect of water temperature on the filtration rate of Japanese pearl oyster, Pinctada fucata martensii. Suisanzoshoku 42:1-6. (In Japanese with English abstract.)

Paik, T. H., T. Hoshino, and T. Kaneda. 1976. Histological studies on mice administered autoxidized oils: acute toxicity. Journal of the Japanese Society of Food and Nutrition 29:85-94. (In Japanese with English abstract.)

Paik, T. H., and T. Kaneda. 1978. Histopathological studies on mice administered autoxidized oils: chronic toxicity. Journal of the Japan Oil Chemists' Society 27:851-855. (In Japanese with English abstract.)

Patton, S., and G. W. Kurtz. 1951. 2. Thiobarbituric acid as a reagent for detecting milk fat oxidation. Journal of Dairy Science 34:669-674. 
Tappel, A. L. 1973. Lipid peroxidation damage to cell components. Federation Proceedings 32:1870-1874.

Tsutsumi, H. 1995. Impact of fish net-pen culture on the benthic environment of a cave in south Japan. Estuaries 18:108-115.

Uchiyama, M., and M. Mihara. 1978. Determination of malonaldehyde precursor in tissues by thiobarbituric acid test. Analytical Chemistry 86:271-278.
Watanabe, T., and Y. Hashimoto. 1968. Toxic components of oxidized saury oil inducing muscular dystrophy in carp. Bulletin of the Japanese Society of Scientific Fisheries 34:1131-1140.

Yokoyama, H. 2002. Impact of fish and pearl farming on the benthic environments in Gokasho Bay: evaluation from seasonal fluctuations of the macrobenthos. Fisheries Science 68:258-268. 